\title{
Pathways of Data-driven Business Model Design and Realization: A Qualitative Research Study
}

\author{
Faisal Rashed \\ Leuphana University of Lüneburg \\ University of Cambridge \\ fr386@cam.ac.uk
}

\author{
Paul Drews \\ Leuphana University of Lüneburg \\ Paul.drews@leuphana.de
}

\begin{abstract}
Maximizing the value from data has become a key challenge for companies as it helps improve operations and decision making, enhances products and services, and ultimately, leads to new business models (BMs). Aiming to achieve the latter, companies take different pathways. Building on a grounded theory research approach, we identified four pathways for designing and realizing data-driven business models (DDBMs). To achieve this goal, we conducted 16 semi-structured interviews with experts from consulting and industry firms. The results fill the gap in the literature on the design and realization of DDBMs and act as a guide for companies.
\end{abstract}

\section{Introduction}

Data have traditionally been perceived as a crucial component of business operations, strategic decision making, and new business development $[1,2]$. The terms under which data have been investigated have varied in the past decades, ranging from business intelligence, business analytics, and big data to big data analytics [1]. Advancements in information technology, especially in machine learning, big data, cloud, and Internet of Things (IoT) technologies, have further increased the importance of data for business development and innovation [2,3]. Many companies are under pressure or are enhancing their traditional business mode with data or to realize new data-driven business models [3, 4]. The latter has led to the emergence of a new research field, which investigates data-driven business models (DDBMs). DDBMs are characterized by data as a key resource, data processing as a key activity, or both [5]. Especially, incumbent companies are expected to rest on huge amounts of unused data treasure, facing several challenges in monetizing their data and seizing new business opportunities [4].
Recent literature reviews of DDBMs revealed a considerable number of publications since 2014 in this thriving research field $[3,4]$. Wiener et al. argued that most studies describe the nature of the DDBM phenomenon and emphasize the scarcity of empirical research [3]. In particular, the "dynamic aspects of BDBM deployments (process perspective)" has received very little attention [3:75]. Furthermore, they emphasized the demand for research capturing stakeholder views and broadening the current focus from Western worldviews to incorporate international perspectives. Additionally, the authors highlighted the value of research on design and realization challenges for practitioners from almost every industry facing the journey for realizing a DDBM.

In this paper, we explore pathways for designing and realizing DDBMs taken by companies in different industries. In this context, we define pathways as generalized courses of DDBM innovation projects. The study focuses on the following research question: What pathways do companies take to design and realize DDBMs? To answer this question, we conducted 16 semi-structured interviews with experts from consulting and industry firms working on DDBM projects in the United States (US), Europe, and Asia Pacific. Based on these interviews and triangulation data from publicly available sources, we collected 19 cases and derived four pathways for designing and realizing a DDBM.

In the next section, we provide an overview of the theoretical foundation of big data analytics (BDA) and DDBMs. We then describe how we conducted the semistructured interviews and clustered the cases to derive pathways for designing and realizing DDBMs. The case clusters and derived pathways are presented before we conclude the discussion and provide practical recommendations for each pathway. We then discuss the study limitations and implications.

\section{Theoretical foundations}

\subsection{BDA and DDBM}


Data have long been acknowledged as a key driver for business and have received considerable attention from the information system discipline $[6,7,8,9]$. In research, the topic has been investigated under several terms ranging from business intelligence, business analytics, and big data to big data analytics [1]. Scholars have advanced the research on BDA from only the technological perspective, defined by the four characteristics volume, variety, velocity, and veracity as a multisided socio-economic phenomenon $[3,6,10]$.

Researchers have examined the potential value from data in three major areas: improved decision making, enhanced products and services, and new BMs [11]. Regarding the last, the latest technological advancements have contributed to the recent call for new DDBMs. The definitions of a DDBM proposed in the literature commonly states that data must be an essential component. Accordingly, Hartmann et al. defined a DDBM as "a business model that relies on data as a key resource" [5:6]. Bulger et al. [12] and Brownlow et al.[13] similarly emphasized the fundamental role of data for DDBMs. Schüritz and Satzger argued that a clear threshold of required data for a DDBM is not defined and that companies shift from a traditional BM to a DDBM, with increased application of the data for the value proposition [14]. However, other scholars such as Wiener et al. [3], distinguish between updating the existing BM with data and developing new models. In this study, we clearly distinguish between enhancements of existing BMs and new DDBMs that are centered on data (data as a key resource and/or data processing as a key activity).

Business modeling techniques are used to represent the conceptual structure of any business. Several modeling frameworks, varying in characteristics and components, have been proposed. The most popular BM framework is the Business Model Canvas (BMC) [15], comprising nine components: partners, key activities, key resources, value proposition, customer relationships, channels, customer segments, cost structure, and revenue stream. The conceptualization and definition of DDBMs rely on the BMC, with data as a key resource and/or with key activities focusing on data processing. Research on DDBMs is still at an early stage.

\subsection{Related work}

To identify potential relevant related work, we conducted a structured literature review, following a methodology proposed by vom Brocke et al. [16]. We queried the following databases with keyword searches: (1) AIS Electronic Library, (2) EBSCO Host Business Source Complete, (3) Google Scholar, (4) IEEE Xplore,
(5) JSTOR, (6) Science Direct, and (7) Web of Science. As the DDBM is an interdisciplinary field, the research is reflected in the intersection of BM and big data [11]. The search comprised keywords covering both areas. The keywords "data-driven" and "business model" were selected. To extend the literature search, the terms "big data" and "analytics," which are associated with "datadriven," were also integrated in the search. This led to a total of three search strings (e.g. "big data business model"). All hits were screened based on their titles and abstracts (see Table 1). The first 100 hits from Google Scholar were considered, acknowledging their decreasing relevance. Irrelevant, duplicate, and nonpeer-reviewed results were excluded. The remaining 45 articles were reviewed based on their full texts.

Table 1. Literature search

\begin{tabular}{l|l|l|l}
\hline \multicolumn{1}{c}{ Database } & \multicolumn{1}{c}{ Hits } & Results & \multicolumn{1}{c}{ Revant } \\
\hline AIS & 51 & 12 & 9 \\
\hline EBSCO & 61 & 8 & 0 \\
\hline Google Scholar & 100 & 7 & 4 \\
\hline IEEE & 81 & 10 & 3 \\
\hline JSTOR & 0 & 0 & 0 \\
\hline Science Direct & 196 & 4 & 0 \\
\hline Web of Science & 141 & 4 & 1 \\
\hline \multicolumn{2}{l}{} & 45 & 17
\end{tabular}

We analyzed the 17 articles concerned with DDBMs and conducted a forward and backward search. To identify literature on designing and realizing DDBMs, we considered only articles that focused on this topic. This means we considered only articles that focused on DDBM design and realization. In particular, we found three insightful structured literature reviews $[3,4,8]$, six theoretical framework, method, and concept-building articles $[5,14,17,18,19,20]$, and two empirical studies $[21,22]$. As part of a structured literature review, Günter et al. [8] presented an example of a European postal service organization failing to realize its DDBM, highlighting common pitfalls. Elevating the research on process models and frameworks, Schüritz and Satzger [14] derived patterns for DDBMs. Similarly, Hartmann et al. [5] proposed a framework for DDBMs used by startup firms. An architectural and transformative perspective was taken by Vanauer et al. [18], who developed a methodology for realizing DDBMs drawing on enterprise architecture management and business model generation techniques. Dedicated empirical research was conducted by Chen et al. [22] during the transformation of the Lufthansa BM, emphasizing critical success factors for the pathway taken by the airline. Similarly, Najjar and Kettinger [21] conducted a case study based on a U.S. retailer realizing DDBMs. The data monetization journey was described in four stages of data value realization. However, both studies were only single case studies. 
The literature on DDBMs is still in its infancy. A limited number of articles address this topic with most contributions emerging within the past 5 years $[3,4]$. The design and realization of DDBMs in particular, which was addressed by only two articles, lack empirical research [3]. We complement the literature with empirical research on multiple cases from global companies.

\section{Research design}

\subsection{Method}

The goal of this study is to reveal pathways companies take to design and realize DDBMs. Drawing on Gregor's work, we want to explain "why" and "how" companies embark on realizing DDBMs [23]. Considering the novelty of DDBMs for academia and practice, we planned to conduct qualitative research. Our approach was to derive theory drawing on the ideas of grounded theory proposed by Corbin and Strauss [24]. We conducted semi-structured interviews with experts from consulting and industry firms to develop a causal theory on DDBM endeavors. Each interviewee has a track record of data monetization projects. We analyzed the data as we collected them. We adjusted the interview guide based on our experience from the first meetings and again after one third had been conducted in step with the insights we gained. Choosing a semistructured interview approach gave us the opportunity to set the direction of the research as we collected the data. Drawing on Myers and Newman' recommendations allowed us to foresee common pitfalls of qualitative interview research [25].

The unit of analysis is a company case for designing and realizing a DDBM. A case can comprise multiple projects, and multiple cases can occur within one company. With the goal of understanding what pathways companies choose, we structured the interview questions regarding two phases: designing and realizing DDBMs. These phases were derived from the literature on designing and realizing DDBMs [18, 19]. We refined the questions as we proceeded. The interviewees reported on their previous DDBM projects. First, they described the background and context of the project. Then we asked about their approach to DDBM design, before tapping into the DDBM realization phase. We documented the interviewees' experiences in case examples.

\subsection{Data}

Between November 2019 and May 2020, we conducted 16 semi-structured expert interviews. All interviews were recorded, transcribed, and coded by the authors. Except for IP5, which was a physical meeting, all interviews were conducted remotely via internet communication tools. We started with an initial list of interviewees leveraging our professional network, who named well-fitting candidates with expert reputations. This allowed us to get a set of practitioners with diverse cultural, gender, and regional perspectives. The interviewees have extensive experience in crossindustry firms as well as consulting firms with different specialization, and included participants from leading consulting companies such as McKinsey, Bain, and Boston Consulting (MBB), as well as the Big Four companies and large IT consulting firms. We included practitioners from various levels but focused on senior management after the first results demonstrated their broader perspective on the perceived factors (less senior tend to focus on one work package). We acknowledged that the interviewees have different backgrounds and expertise, and we modified the questions as required. For example, interviewees had either a stronger business or IT view on the cases they reported. Analyzing the interview data as we proceeded and asking for additional interviewees allowed us to look for specific experiences, which we might have missed. For example, after the eighth interview, we acknowledged a regional limitation as we collected only European cases. We then specifically asked for cases outside Europe. Similarly, we emphasized the female perspective after taking into account the male dominance. The participant list is shown in Table 2.

Table 2. Interview participants

\begin{tabular}{ll|l|l}
\hline IP & Role & Organization & Experience \\
\hline 1 & Senior Manager & IT Consulting & +8 years \\
\hline 2 & Director & IT Consulting & +20 years \\
\hline 3 & Senior Manager & IT Consulting & +10 years \\
\hline 4 & Director & Insurance Co. & +20 years \\
\hline 5 & Director & MBB & +12 years \\
\hline 6 & Senior Manager & MBB & +10 years/ PhD \\
\hline 7 & Director & MBB & +20 years/ PhD \\
\hline 8 & Consultant & IT Consulting & +4 years \\
\hline 9 & Director & IT Consulting & +15 years/ PhD \\
\hline 10 & Director & IT Consulting & +20 years \\
\hline 11 & Director & IT Consulting & +15 years/ PhD \\
\hline 12 & Senior Manager & IT Consulting & +10 years/ PhD \\
\hline 13 & Director & Public Services & +12 years/ PhD \\
\hline 14 & Senior Manager & Financial Services & +10 years \\
\hline 15 & Senior Manager & Big Four & +8 years \\
\hline 16 & Senior Manager & Life Science & +8 years/PhD \\
\hline
\end{tabular}

The interviews were scheduled for 60 minutes. Depending on the course, the interviewee reported one or two cases. We asked for "success" and "failure" cases, referring to designing and realizing DDBMs. Success constitutes the delivery of the project within time, scope, and budget. At the end of each interview, we asked for publicly available data sources for 
triangulation. Furthermore, we applied internet research to gather additional triangulation data.

\subsection{Analysis}

To construct a coherent theory based on the gathered data, we draw on the grounded theory as proposed by Corbin and Strauss [24]. We applied an open coding approach and selected ATLAS.ti for tool support. Not having a specific framework in mind, we conducted the interviews openly. However, we structured the questions in terms of the DDBM design and realization phases [18, 19]. To uncover relations among the categories, we reassembled the data that had been broken up during the open coding. For this, we applied axial coding as described by Corbin and Strauss [24]. Based on the factors the interviewees described about the case context and the steps for designing and realizing DDBMs, we refined the questions and built theoretical constructs. Dimensions mentioned frequently within the analysis of the first set of data were asked about specifically in the following interviews. After the ninth interview, we were able to build clusters for the collected cases. We used the remaining interviews to test the case cluster with the interviewees.

We acknowledge the threats to validity. Considering the four types of validity as described by Maxwell [26], we put great effort to ensure the interviewees could speak openly and were not in a conflicting situation. The developed concepts were critically assessed by both authors. We triangulated the interview results with publicly available data.

\section{Results}

In this section, we present an overview of the cases, and then we describe the context and the "why" behind the endeavors. Following that, we summarize the pathways identified for designing and realizing DDBMs, which describes the "how."

\subsection{Insights from expert interviews}

Discussing the definition of a DDBM with the interviewees revealed practitioners' differing interpretations of this term. Analogous to the perspectives in the literature, some interviewees shared our view of a DDBM as a new BM with data as the key resource and/or data processing as a key activity. Others interpreted the gradual enhancement of the traditional BM with data as a DDBM as well. The latter group used the term data monetization as a synonym, stating the meaning as "maximization of data's commercial value" [IP9]. However, it transpired that even for this group the ultimate goal of DDBM projects is the establishment of new BMs. Our definition of DDBM did not change, but we acknowledge that the gradual enhancement of the traditional BM can be interpreted as a transitional step toward a DDBM. When we asked the interviewees about the DDBM cases they had experienced, they highlighted the scarcity of DDBM cases in line with our interpretation. Most DDBM cases reported imply the ambition for a new BM centered on data but started with use cases (UCs) focusing on the enhancement of the existing BM. As an explanation for this phenomenon, the interviewees emphasized that "improving the existing services, products, and operations is more obvious to the business, easier to grasp, and bears less risk" [IP11]. Only four cases described the establishment of a new DDBM.

The companies behind the reported cases are large regional and global players whose origin and main business are in Asia Pacific, Europe, and North America. Two of the four DDBM cases described European firms, and two described Asian Pacific firms. The majority of the cases were in the insurance, financial services, and life sciences industry. The projects were sponsored either directly by the chief executive officer (CEO), through a joint sponsorship between the business unit (BU) and the chief information officer/chief digital officer (CIO/CDO), or by only the BU or $\mathrm{CIO} / \mathrm{CDO}$. The interviewees reported that the endeavors were motivated by a clear business opportunity, a common vison for the company, their digital strategy, the BU vision, or as a competitive response. Four financial sources were described. The first was the business unit budget, which is relatively small compared to the other sources but is under full control of the business unit. The second was the budget allocated to the digital transformation of the organization, comprising multiple digital initiatives. The third was investments in the entire organization to transform toward a common vision. The fourth was investment in the exploitation of new business opportunities. The business unit initiating the project chose the expected value and application of the data. The case list is shown in Table 3.

\subsection{Case clusters}

Among all interviews, two contextual dimensions determined the case clusters: the degree to which the data were understood and the degree of self-incentive. These two dimensions allow the allocation of the cases into four quadrants. For cases within the same cluster, we noticed correlations between the motivation to initiate the endeavor, the sponsoring entity, the lever of data value, and the funding allocation. 
Cases comprising companies with high data understanding and low self-incentive (see Figure 1: quadrant I) start the journey toward a DDBM by developing use cases for BDA. The initiatives are

\section{Table 3. Case list}

\begin{tabular}{|c|c|c|c|c|c|c|c|}
\hline$C$ & $I P$ & Industry & Reg./Glo. & $H Q$ & Motivation & Sponsor & Funding \\
\hline 1 & IP1 & Insurance & Local & $\mathrm{D}$ & Digital strategy & $\mathrm{CDO} / \mathrm{CIO}$ & Digital transformation \\
\hline 2 & IP2 & FS & Global & AUT & Digital strategy & $\mathrm{CDO} / \mathrm{CIO}$ & Digital transformation \\
\hline 3 & IP2 & FS & Global & AUT & Competitive response & $\mathrm{CDO} / \mathrm{CIO}$ & Digital transformation \\
\hline 4 & IP3 & Insurance & Global & $\mathrm{D}$ & Digital strategy & $\mathrm{CDO} / \mathrm{CIO}$ & Digital transformation \\
\hline 5 & IP4 & Insurance & Global & $\mathrm{CH}$ & Competitive response & $\mathrm{CDO} / \mathrm{CIO}$ & Digital transformation \\
\hline 6 & IP5 & FS & Global & $\mathrm{CH}$ & BU vision & Head of M\&S and CDO & BU budget \\
\hline 7 & IP5 & FS & Global & $\mathrm{CH}$ & BU vision & Head of HR & BU budget \\
\hline 8 & IP6 & $\mathrm{IE}$ & Global & $\mathrm{D}$ & Company vision & CEO & Trans. budget \\
\hline 9 & IP7 & Insurance & Global & $\mathrm{CHN}$ & Clear business opportunity & CEO & New business opportunity \\
\hline 10 & IP8 & Chemicals & Global & $\mathrm{D}$ & Digital strategy & $\mathrm{CDO} / \mathrm{CIO}$ & Digital transformation \\
\hline 11 & IP9 & LS & Global & $\mathrm{CH}$ & BU vision & Head of R\&D and CDO & BU budget \\
\hline 12 & IP9 & $\mathrm{LS}$ & Global & $\mathrm{D}$ & BU vision & Head of M\&S and CDO & BU budget \\
\hline 13 & IP10 & Insurance & Local & US & Digital strategy & $\mathrm{CDO} / \mathrm{CIO}$ & Digital trans. \\
\hline 14 & IP11 & FS & Global & AUS & Clear business opportunity & CEO & New business opportunity \\
\hline 15 & IP12 & Energy & Local & $\mathrm{D}$ & Clear business opportunity & $\mathrm{CEO} / \mathrm{CIO}$ & New business opportunity \\
\hline 16 & IP13 & PS & Local & $\mathrm{D}$ & Digital strategy & $\mathrm{CDO} / \mathrm{CIO}$ & Digital transformation \\
\hline 17 & IP14 & FS & Global & $\mathrm{CH}$ & Digital strategy & $\mathrm{CDO} / \mathrm{CIO}$ & Digital transformation \\
\hline 18 & IP15 & $\mathrm{LS}$ & Global & $\mathrm{D}$ & Digital strategy & $\mathrm{CDO} / \mathrm{CIO}$ & Digital transformation \\
\hline 19 & IP16 & $\mathrm{LS}$ & Global & $\mathrm{UK}$ & BU vision & Head of R\&D and CDO & Trans. budget \\
\hline
\end{tabular}

$F S=$ Financial Services $;$ IE = Industrial Equipment $:$ LS = Life Science $; P S=$ Public Services

funded by the business units which also have the analytical capabilities. These companies tend to develop use cases in a lab environment with external parties to justify larger investments once the value was proven. The endeavor is motivated by the BU's vision and sponsored by the BU lead with support from the $\mathrm{CIO} / \mathrm{CDO}$. Cases comprising companies with low data understanding and high self-incentive (see Figure 1: quadrant II) invest in the technology first. These companies have little understanding of their data and potential application fields but have decided to heavily invest in BDA as part of their digital initiatives. Great effort is made to understand technology options and solution functionalities. However, the BDA use is described with short use cases, and the technology selection is prioritized. The endeavor is sponsored by the head of the IT department and funded by the budget for the digital transformation. Companies with low data understanding and low self-incentive (see Figure 1: quadrant III) remain in a pending state. They invest in use case development within the business units and conduct software selection projects but do not take the next step toward a DDBM. These companies tend to initiate cases reactively as a competitive response and under digital pressure. On the opposite side are cases in companies with a high degree of data understanding and self-incentive (see Figure 1: quadrant IV). Having a clear vision and deep analytical capabilities allow these companies to invest in new DDBMs immediately. The initiatives are sponsored by the CEO and financed with funds for new business opportunities. The new DDBM is either integrated into the existing organizational structure, or a new company is established putting the new DDBM forward as a startup. Use case- and technology-centric cases have the ambition to develop

DDBMs as goal, "BDA projects pave the way for DDBM" [IP2]. Similar statements were made by IP1, IP3, IP4, IP8, and IP9. We received use case descriptions from IP1 and IP9. The use cases for gradual enhancement of the traditional business model were very detailed, but the potential new DDBMs were described on a higher level. Furthermore, the realization of the use cases was suggested in a sequence beginning with the enhancement of the traditional BM and introducing the DDBM as a so-called "north star." For example, the use case of a pharma company for datadriven automation that would lead to cost optimization was described in detail with quantifications, but the use case that would imply a new DDBM was outlined with less detail and quantification ranges [IP9].

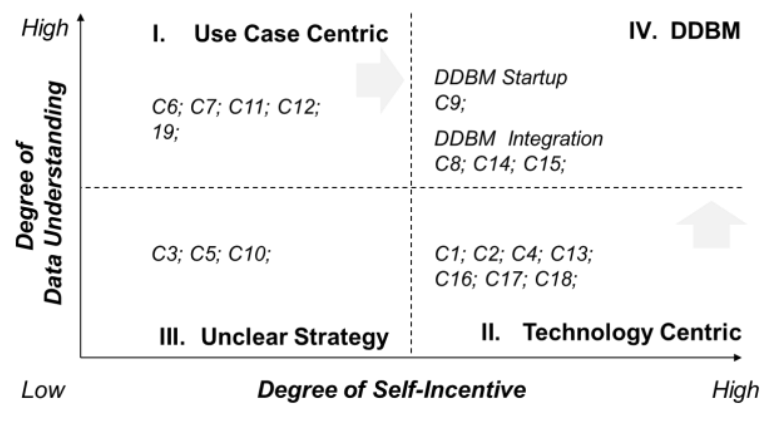

Figure 1. Case clusters 


\subsection{Pathways for DDBM design and realization}

The interviewees described the approaches that were taken to gain value from data. We identified four pathways. For quadrant I cases, we theorized a use casecentric pathway. Similarly, we derived a technologycentric pathway for quadrant II cases. Cases in quadrant III did not demonstrate a clear approach; they remained in a vague state not proceeding with a clear strategy for design and realization. For quadrant IV cases, two distinct pathways were reported by the interviewees. The companies in these cases either integrated a new DDBM into their existing structure or established a new company dedicated to driving the DDBM in a startup setup.

4.3.1. Use case centric. Beginning with the use cases implies the vital role of the BU in the pathway, who fund the initial efforts with their budget (see Figure 2). Use cases are often ideated, selected, and prioritized with external support. Often, consultants bring in use case catalogues from various industries and additional capacity. Ideally, the use cases are sequenced in order to allow gradual development of the required capabilities. Based on the identified use cases, a solution architecture is designed considering existing data resources, technological and analytical capabilities, as well as organizational and structural enablers. A minimum viable product (MVP) is developed in a lab environment to test the feasibility. Once the MVP is approved by the leadership, the implementation begins with the IT driving the process. Collaboration between the business unit and the IT department during the process is crucial for successful MVPs. For example, IP 5 provided two cases with the same client but with different BUs. The case with marketing and sales had early and extensive IT involvement which in the end made the MVP successful and led to implementation.

\begin{tabular}{|c|c|c|c|c|}
\hline & $\begin{array}{l}\text { Use Case } \\
\text { Development }\end{array}$ & $\begin{array}{c}\text { Solution } \\
\text { Architecture }\end{array}$ & & \\
\hline BU & $\begin{array}{l}\text { Drive use case } \\
\text { ideation, } \\
\text { development, } \\
\text { prioritization }\end{array}$ & $\begin{array}{l}\text { Support decision } \\
\text { making with clear } \\
\text { business } \\
\text { requirements }\end{array}$ & $\begin{array}{l}\text { Co-design prototype } \\
\text { with minimum } \\
\text { requirements }\end{array}$ & $\begin{array}{l}\text { Support decision } \\
\text { making with clear } \\
\text { business } \\
\text { requirements }\end{array}$ \\
\hline IT & $\begin{array}{l}\text { Provide required } \\
\text { information on } \\
\text { technology and data } \\
\text { landscape }\end{array}$ & $\begin{array}{l}\text { Drive solution } \\
\text { architecture } \\
\text { development }\end{array}$ & $\begin{array}{l:}\text { Co-design prototype } \\
\text { with minimum } \\
\text { requirements }\end{array}$ & $\begin{array}{l}\text { Drive the } \\
\text { implementation }\end{array}$ \\
\hline $\begin{array}{l}\text { External } \\
\text { Support }\end{array}$ & $\begin{array}{l}\text { Consultants } \\
\text { supporting with use } \\
\text { case catalogues }\end{array}$ & $\begin{array}{l}\text { Consultants } \\
\text { supporting with } \\
\text { technology } \\
\text { expertise }\end{array}$ & $\begin{array}{l}\text { Consultants } \\
\text { supporting the MVP } \\
\text { development }\end{array}$ & $\begin{array}{l}\text { Consultants } \\
\text { supporting tech } \\
\text { selection and } \\
\text { implementation }\end{array}$ \\
\hline
\end{tabular}

Figure 2. Use case centric

The theorized approach was grounded in five cases within the life science and financial service industry of which one is in the transition from solution architecture toward an MVP (C12) and one in the UC development stage (C19). The latter is concerned with the R\&D BU of a life science company that leverages data to identify biomarkers for clinical trials. The focal company acquired a niche firm for identifying data-driven biomarkers and struggled with integration efforts and parallel use case development [IP16].

4.3.2. Technology centric. Companies beginning with technology capability development decided to invest heavily in BDA platforms as part of their digital strategy. The business requirements are blurry and poorly derived from high-level use cases. The process is initiated with technology selection efforts, considering internal and external capabilities (see Figure 3). Within this phase, a request for proposal (RFP) is addressed to providers which have been selected by external consultants. Technology is selected with limited understanding of the business requirements. The second phase is the proof of concept conducted with the preferred vendor and with the second-best choice put on hold. Subsequently, the implementation follows. Selecting the most sophisticated solution to provide best-in-class technology capabilities was stated as a common strategy. For example, a financial services company decided to invest in a BDA platform as part of their digital strategy for data-driven banking. The decision to implement Hadoop as the most sophisticated platform was made without extensive technology fit assessments. The use cases for the data lake utilization were detailed out during the project. As it turned out, the implemented solution was very advanced and not required for the developed use cases. The interviewee highlighted "the investment was not justified" [IP2].

The approach illustrated in Figure 3 was derived from seven cases, each describing the three phases. However, we want to give one more interesting example within the public services industry. As part of smart city initiatives, many sensors have been implemented within a Germany city. The funds were made available for this purpose by the government as part of their smart city strategy. The interviewee and his team were in the process of implementing a platform to leverage the increasing data sources for enhanced and new services. Use cases were developed at a high level, for example, for navigating within the city for blind people, or tracking and dynamically planning the routes for garbage and clothes collection [IP13]. 


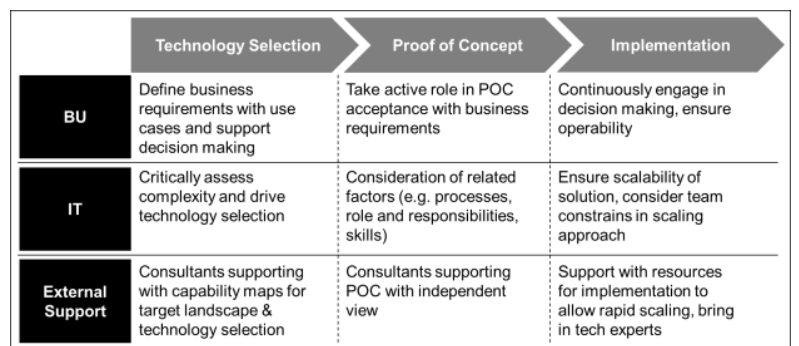

Figure 3. Technology centric

4.3.3. DDBM integration. Transforming an organization to integrate the new DDBM into existing structures requires a clear business opportunity, a common vision, and CEO sponsorship. Based on the cases the interviewees reported, we theorized a threephase process (see Figure 4). It begins with the DDBM design, which is supported by external consultants infusing the ideation process with relevant industry and cross-industry DDBM cases. This process step results in a populated BM comprising the relevant fact of the identified business opportunity. Based on this design, an MVP is initiated presenting early tangible results. Once the MVP reaches certain maturity, it gets passed to the implementation stage, where the developed product is scaled for commercialization. The pathway is grounded in three cases we gathered. First, a German industrial equipment company identified new data-driven services as a future opportunity. The vision was developed with management consultants, enabling the firm to complement their device-centered BM with new datadriven services for maintenance and value-based pricing [IP6]. Second, a global Australian bank was approached by management consultants with an opportunity to sell banking transaction data for targeted offerings. The bank designed a DDBM with the consulting firm and developed an MVP in a trial-and-error approach. Presenting agile and iterative results shortened the time to market [IP11]. Third, an energy provider decided to develop a data monetization platform, allowing customers to purchase data-driven services and service providers to offer services enriched with energy consumption data. This decision to monetize data was motivated by shrinking revenues in the energy industry and technology advancements, such as smart meters, which became a European standard. Anonymized energy consumption data open up many business opportunities for various industries. For example, disaggregating the energy consumption data of an elderly person allows conclusions to drawn if the oven was turned on for more than 3 hours. The DDBM was designed with the BMC for platform economies, which incorporates multisided customer and provider perspectives. The interviewee reported that the project is ongoing and transitioning toward the development of an MVP [IP12].

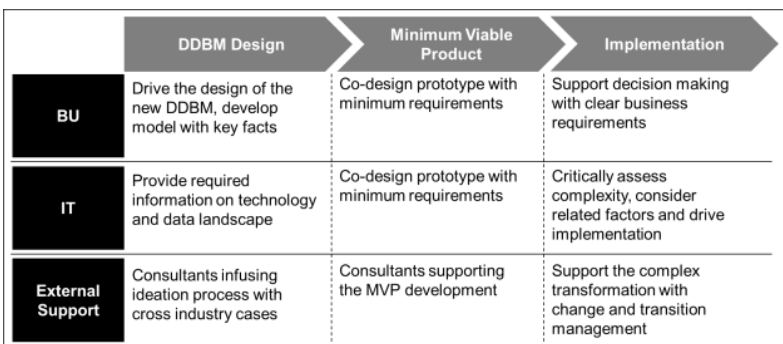

Figure 4. DDBM integration

4.3.4. DDBM startup. In contrast, the establishment of a DDBM through a new company requires a different approach (see Figure 5). However, a clear business opportunity and CEO sponsorship are vital here as well. Having a clear understanding of the data and its monetization opportunity paired with willingness to invest allow new revenue streams to be harvested. This boldness leads to the decision to set up a new company. The capabilities are built up from scratch. Ideally, the new subsidiary remains completely separate, conceptually and spatially. Access to the data is granted through APIs. The team works in a startup fashion with end-to-end responsibilities from designing the DDBM to realizing it. We used the term realization to emphasize the difference between the implementation phase in an enterprise, which is often conducted by the IT department. In contrast to the previous pathways, there are no conceptual breaks during this process caused by consulting firm or organizational handovers. For example, an insurance company headquartered in China decided to monetize their 10 years of insurance data from 650 million clients. Based on this idea, a company was established with newly hired employees. A team of 20-30 members with special capabilities worked on the DDBM from design to realization in an agile startup fashion. The DDBM was detailed during the process resulting in an MVP that was discussed early with potential clients. Data were extracted from the parent company as required. The architecture was designed to allow rapid scaling with minimum effort. The interviewee highlighted the importance of keeping the company separate and not using the prevailing infrastructure and capabilities of the parent company. This would increase cost and complexity, and furthermore, the team would not have had the innovation level that such an endeavor requires [IP7].

Separating the DDBM into a new startup at a later stage might be possible but implies many challenges. Therefore, we want to emphasize three important considerations for the decision to set up a new company. We revisit the DDBM integration case with an energy provider mentioned above where these considerations are under discussion. The first consideration is human capital. The DDBM was designed by an internal company team who claimed to proceed with the 
realization. The team lead persisted to retain his team members. However, it was questioned whether they had the required skillset to ramp up the DDBM in an agile startup way. The second consideration was the technology landscape. The DDBM design was based on the prevailing IT architecture, which turned out to be a threat for DDBM scaling due to legacy systems and other architectural constraints. The third consideration was the ecosystem. The new DDBM required collaborations with partners but also competitors. To disaggregate energy consumption data, the focal company required energy profile data from various device manufacturers. Furthermore, to train the algorithms with rich test data sets, the focal firm depended on smart meter data from other energy providers.

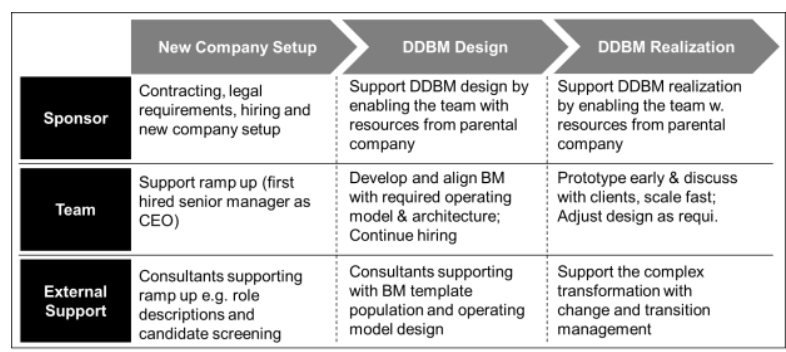

Figure 5. DDBM startup

\section{Discussion}

Conducting interviews with DDBM practitioners from around the globe allowed us to report the gathered cases in a descriptive way. We presented a list of 19 cases in various industries and in cooperation with varying consulting firms. Furthermore, we were able to derive pathways for designing and realizing DDBMs grounded in the empirically collected cases. The novelty of the DDBM field in academia and practice makes this research unique and of great value to both.

Following academia's call for empirical research and practitioners' demand for reference cases, we presented 19 cases. The results complement the existing literature on DDBM methods and concepts [14, 17, 18, 19, 20]. Two recent literature reviews on DDBMs revealed the gap in detailed design and realization knowledge $[3,4]$. We complement the literature by presenting four pathways of DDBM innovation. These pathways deepen the knowledge of DDBM processes and can refine the method suggested by Vanauer et al. for designing and realizing DDBMs [18]. The research on DDBM tool support conducted by Kühne and Böhmann can also be enriched with the proposed pathways and interview results, as we provide detailed knowledge of the approaches taken for DDBM design and realization [20]. During the interviews, it transpired that "value is often generated with DDBM, the important question is if the potential revenue streams behind the DDBM leads to profitable operations considering the associated costs" [IP13].

Several important practical recommendations emerged in the expert interviews. Although interviewees reported about pathways, they stressed the importance of specific considerations that had a great impact on the course of the DDBM cases. We believe sharing these important considerations allows practitioners to navigate the DDBM journey and gives researchers insights into practice. In the following, we present these important practical recommendations for each pathway (see Table 4).

Companies taking the use case-centric pathway benefit from central organization of the use cases. BUs tend to operate independently from each other and develop MVPs in lab environments that cannot be implemented in production due to the effort exceeding the potential value. Early and continuous involvement of the IT department can prevent the latter, especially when it comes to considering prevailing data assets, technology capabilities, and infrastructure. Use case realization should be sequenced considering the required and existing capabilities. Teams should have end-to-end responsibility to prevent conceptual breaks due to handovers and external party fluctuation.

Taking the technology-centric pathway requires a clear understanding of the business requirements for the BDA platform, as well as continuous BU involvement during the technology selection process. The decision to invest in a D\&A platform should be critically assessed in terms of the requirements. Furthermore, it is vital to conduct the technology selection provider agnostic. A critical assessment of the complexity and the effort for the potential transformation is essential. This includes a view on the effort to scale the solution for the business need, as well as the effect on the business model, operating model, processes, skills and talents.

Integrating the new DDBM within existing organizational structures requires a complex transformation. Senior management support is vital to ensure the thriving business model is not smothered by the traditional business model, especially when it comes to data access across the organization. The prevailing processes, applications, and infrastructure must be understood. A clear design for the target state of the organizational and technological structures is vital. Efforts for developing talent, skills, and processes should not be underestimated. Breaks from the organizational vision over business model design and realization should be minimized.

Establishing a new data-driven company brings many opportunities which should be well exploited. Separating the new company from the parental company 
was mentioned as the most important factor. This includes minimization of the parental infrastructure and capabilities. The team should be newly hired with talents matching the demand of a startup for highly skilled and innovative roles. End-to-end responsibility and agile ways of working are key requirements for the team. Results should be discussed early in the process with the client, ensuring a co-design of the data products and services. The architecture of the new company has to be designed for rapid scaling.

Table 4. Practical recommendations

\begin{tabular}{l|l}
\hline Pathway & Practical recommendations \\
\hline Use case & - Centrally coordinate use cases \\
centric & - Sequence use cases to allow gradual capability \\
& development \\
& - Consider implementation efforts in MVP phase \\
& - Consider prevailing technology landscape, \\
& processes, and analytical capabilities \\
& - Minimize conceptual internal organizational and \\
& consulting firm breaks (handovers) \\
& - Involve IT early and continuously \\
\hline Tech. & - Set clear business requirements \\
centric & - Continuously involve the BU(s) \\
& - Conduct provider-agnostic technology selection \\
& - Critically asses the investment decision \\
& - Consider related factors (e.g., processes, role, and \\
& responsibilities, skills) \\
& - Critically asses the complexity \\
\hline DDBM & - Ensure senior management support \\
integration & - Consider prevailing technology landscape, \\
& processes, and analytical capabilities \\
& - Consider transformation effort from structural, \\
process, skill, and technology perspectives \\
& - Consider impact of dominant/traditional business \\
& model \\
& - Consider innovation level of team members \\
& - Minimize conceptual internal organizational and \\
& consulting firm breaks (handovers) \\
\hline startup & - Separate new DDBM firm from parent company \\
& conceptually and spatially \\
& - Minimize utilization of parent company \\
& capabilities and infrastructure \\
& - Design an enterprise architecture ready for rapid \\
& scaling \\
& - Ensure end-to-end responsibility \\
& - Establish agile ways of working with early client \\
involvement for prototype testing
\end{tabular}

\section{Conclusion and outlook}

Data have proven their value as a key business driver. The latest technology advancements have further elevated the importance of data for operational efficiency, business development, and innovation. However, DDBMs is a new field of research with little empirical research [3, 4, 22]. Building on a grounded theory approach, we identified four pathways for designing and realizing DDBMs. To achieve this goal, we conducted 16 semi-structured interviews with experts from consulting and industry firms. The contributions of this study are twofold. First, we provided a descriptive overview of 19 cases representing the journeys companies take for designing and realizing DDBMs. For this, we gathered the perspectives of a diverse set of practitioners revealing their understanding of DDBMs and the relation to intermediate BDA projects for DDBM introduction. Second, we theorized the causality between the "why" and "how" of DDBM design and realization. Case clustering was proposed, taking the reported dimensions into account. Within the case clusters, the pathways companies take for DDBMs were derived.

The results of this research have implications for academia and practice alike. For academia, we contribute to the gap in the literature and gathered 19 cases for DDBM design and realization, providing empirical insights. The pathways lay the foundation for scholars to expand the thriving literature on DDBM design and realization. For practitioners, the results serve as guide to navigate through the unexplored field of DDBM design and realization. It helps to understand the state of the art and the selection of an approach to DDBMs. Furthermore, common challenges and important considerations can be foreseen, learning from these cases.

This study has several limitations. Drawing on Maxwell [26], we structured the limitations of this qualitative research in four types. The first limitation is evaluative. We acknowledge the threat to validity based on the dependency on individual interpretation of the reported events. Although we validated the described facts with triangulation data, the threat cannot be completely diminished. The second limitation is theoretical limitations. We applied a semi-structured interview approach to collect data with an open mind. However, this research was infused by our previous research on the topic. Therefore, the validity of the prevailing theoretical concepts imposes a threat as well. The third limitation was interpretative. The case clustering and the derived pathways are imbued with an interpretation of the data. Although both authors processed the data independently, and the results were challenged with two directors from management consulting firms, the data were subjectively interpreted. The fourth limitation was descriptive. We acknowledge the threat to validity imposed in the description process. All results were written and interpreted by both authors iteratively. The working paper was sent to two interviewees to gather additional feedback. The number of interviews and cases was limited. However, we analyzed the data as we proceeded with the interviews. After the ninth interview, we were able to derive the case clusters and pathways. The remaining interviews were used to test the concepts. 
Additional research is required to further examine the DDBM pathways to propose detailed methods for each pathway. Moreover, the intersection of DDBM and related research fields must be studied in light of the proposed pathways. Our future work will focus on the enterprise architecture modeling and management support for the pathways for designing and realizing DDBMs.

\section{References}

[1] H. Chen, R.H.L. Chiang, and V.C. Storey, "Business Intelligence and Analytics: From Big Data to Big Impact", MIS Quarterly, 2012, pp. 1165-1188.

[2] E. Brynjolfsson, and A. McAfee, "Big Data: The Management Revolution", Harvard Business Review, 2012, pp. $1-12$.

[3] M. Wiener, C. Saunders, and M. Marabelli, "Big-data business models: A critical literature review and multiperspective research framework", Journal of Information Technology, 2020, pp. 66-91.

[4] M. Fruhwirth, C. Ropposch, and V. Pammer, "Supporting Data-Driven Business Model Innovations: A Structured Literature Review on Tools and Methods Semantic MediaWiki View Project Multimedia Tagging View Project", Journal of Business Models, 2020, pp. 1-19.

[5] P.M. Hartmann, M. Zaki, N. Feldmann, and A. Neely, "Big Data for Big Business? A Taxonomy of Data-driven Business Models Used by Start-up Firms", Cambridge Service Alliance, 2014, pp. 1-29.

[6] A. Abbasi, S. Sarker, and R.H.L. Chiang, "Big Data Research in Information Systems: Toward an Inclusive Research Agenda", Journal of the Association for Information Systems, 2016, pp. 1-30.

[7] R. Sharma, S. Mithas, and A. Kankanhalli, "Transforming Decision-Making Processes: a Research Agenda for Understanding the Impact of Business Analytics on Organisations", European Journal of Information Systems, 2014, pp. 433-441.

[8] W.A. Günther, M.H. Rezazade Mehrizi, M. Huysman, and F. Feldberg, "Debating Big Data: A Literature Review on Realizing Value From Big Data", Journal of Strategic Information Systems, 2017, pp. 191-209.

[9] B. Baesens, R. Bapna, J.R. Marsden, J. Vanthienen, and J.L. Zhao, "Transformational Issues of Big Data and Analytics in Networked Business”, MIS Quarterly, 2016, pp. 807-818.

[10] C. Dremel, and J. Wulf, "Towards a Capability Model for Big Data Analytics", 13th International Conference on Wirtschaftsinformatik, AIS, St. Gallen, 2017, pp. 1141-1155.

[11] A. Engelbrecht, J. Gerlach, and T. Widjaja, "Understanding the Anatomy of Data-driven Business Models

- Towards an Empirical Taxonomy", Twenty-Fourth European Conference on Information Systems, ECIS, İstanbul, 2016, pp. 1-15.
[12] M. Bulger, G. Taylor, and R. Schroeder, "Data-Driven Business Models: Challenges and Opportunities of Big Data", Oxford Internet Institute, 2014, pp. 1-74.

[13] J. Brownlow, M. Zaki, A. Neely, and F. Urmetzer, "Data and Analytics - Data-Driven Business Models : A Blueprint for Innovation Blueprint for Innovation", Cambridge Service Alliance, 2015, 1-15.

[14] R. Schuritz, and G. Satzger, "Patterns of Data-Infused Business Model Innovation”, Proceedings - CBI 2016: 18th IEEE Conference on Business Informatics, IEEE, Paris, 2016, pp. 133-142.

[15] A. Osterwalder, and Y. Pigneur, Business Model Generation: A Handbook for Visionaries, Game Changers and Challengers, John Wiley and Sons, Inc., Hoboken, 2010.

[16] J. Vom Brocke, A. Simons, B. Niehaves, K. Reimer, R. Plattfaut, and A. Cleven, "Reconstructing the Giant: On the Importance of Rigour in Documenting the Literature Search Process", European Conference on Information Systems, ECIS, Verona, 2009, pp. 2206-2217.

[17] R. Schüritz, S. Seebacher, and R. Dorner, "Capturing Value from Data: Revenue Models for Data-Driven Services", Proceedings of the 50th Hawaii International Conference on System Sciences (2017), Waikoloa, 2017, pp. 5348-5357.

[18] M. Vanauer, C. Bohle, and B. Hellingrath, "Guiding the Introduction of Big Data in Organizations: A Methodology with Business- and Data-driven Ideation and Enterprise Architecture Management-Based Implementation", 48th Hawaii International Conference on System Science, IEEE, Hawaii, 2015, pp. 908-917.

[19] H.-M. Chen, R. Kazman, J. Garbajosa, and E. Gonzalez, "Big Data Value Engineering for Business Model Innovation", 50th Hawaii International Conference on System Sciences, IEEE, Hawaii, 2017, pp. 5921-5930.

[20] B. Kühne, and T. Böhmann, "Data-driven Business Models - Building the Bridge Between Data and Value", 27th European Conference on Information Systems, ECIS, Stockholm \& Uppsala, 2019, pp. 1-16.

[21] M.S. Najjar, and W.J. Kettinger, "Data Monetization: Lessons from a Retailer's Journey”, MIS Quarterly Executive, 2013, pp. 21-32.

[22] H. Chen, R. Kazman, R. Schütz, and F. Matthes, "How Lufthansa Capitalized on Big Data for Business Model Renovation”, MIS Quarterly Executive, 2017, pp. 19-34.

[23] S. Gregor, "The Nature of Theory in Information Systems", MIS Quarterly: Management Information Systems, 2006, pp. 611-642.

[24] J.M. Corbin, and A. Strauss, "Grounded Theory Research: Procedures, Canons, and Evaluative Criteria", Qualitative Sociology, 1990, pp. 3-21.

[25] M.D. Myers, and M. Newman, "The Qualitative Interview in IS Research: Examining the Craft", Information and Organization, 2007, pp. 2-26.

[26] J.A. Maxwell, Qualitative Research Design: An Interactive Approach, SAGE, Washington, 2013. 